Journal of Contemporary Educational Research

Research Article

\title{
The Significance of Geographical Factors in Genealogy to Language Research-Taking Liao's Audio-visual Genealogy as an Example
}

Jiajia Xi

Linguistics and Applied Linguistics, Zhejiang Normal University, Nantong 321000, Jiangsu Province, China

\begin{abstract}
The geographical information reflected in a traditional genealogy mainly has two aspects. On the one hand, it is the administrative division, human geography, and other general environmental conditions of the ethnic group. On the other hand, it points to the specific origin and migration of family members in the family tree. In addition to affecting the formation and evolution of language, these factors will also affect the development trend of language behavior by promoting the psychology of people's geographic identity. From these data, we find that geographic factors in the genealogy have a non-negligible relationship with the geographical spread of the language of the genealogy.

Key words: Genealogy; Administrative Division; Migration History; Dialect Variants; Geographical Identity
\end{abstract}

Publication date: October, 2020

Publication online: 31 October, 2020

*Corresponding author: Jiajia Xi, xjjnus0208@163. com

\section{Introduction}

The corpus of language evolution has long plagued scholars. Whether from the time dimension or the geographical dimension, geographic dialect continuum of a specific area is constantly interacting.Based on the original, multi-dimensional and frequent language contact is an important reality of language proliferation. Since Georg Wenker conducted the first survey of the geography of dialects in 1876, comparative studies of common languages have been limited by the time interval of comparison groups, and real-time events in language evolution cannot be recorded.Because in the evolution of regional languages the diffusion of many innovative elements is very slow, they cannot be confined to the life span of a single generation. The apparent time method commonly used in the study of Chinese dialects. An obvious contradiction is that the objects of comparative analysis must be people of the same era, which limits the comparability of real-time research.

As a real-time corpus for language research, the realization of storage and extraction functions is a problem that the Chinese Dialect Audio-visual Genealogy Project hopes to solve. The development of this audio-visual genealogy project is mainly based on a mature and well-developed genealogy system that fully reflects its geographical relationship. It applies the blood relationship system in the genealogy to break through the time-limited interval surveys, thereby supporting comparative research based on realtime survey data of several generations and realizing language evolution. In this way recording of language innovation spreads throughout real-time data collection and corpus storage ${ }^{[1]}$. This article mainly discusses one of the theoretical supports for the development of audiovisual genealogy - the study of language variation needs to combine geographical factors in the genealogy to truly explore the mechanism of language innovation diffusion in specific regions from a micro perspective.

\section{Administrative Division}

To interpret the development and change of language from a geographical perspective, it is necessary 
to clarify the change from one level to another in the dialect continuum caused by the historical changes of language - that is, what happen when neighborhood effect in the wave-like diffusion of language innovation ${ }^{[2]}$. Therefore, we must understand in detail the local history of the language area where the continuum to be studied is located, especially the specific boundaries of ancient administrative divisions and the migration history of residents, clarify the relationship between autonomy and subordination in the dialect continuum, and determine whether there is a correlation with dialect division. You Rujie and Zhou Zhenhe used the situation in Zhejiang Province as an example to explain the evolution of political regions. Through a comparison of 25 phonetic features, they analyzed the historical reasons for the consistency of administrative divisions and dialect divisions. They believe that in areas with relatively stable political regions in history, the geographical division of dialects and historical administrative geography have an observable consistency, and the fuzzy boundaries of dialects can be roughly inferred from historical administrative geography ${ }^{[3]}$. Documents related to the history of China's administrative history are numerous. However, these documents, especially the local chronicles, mainly focus on the political, economic and cultural centers of various places. Affected by the administrative division system, urban centers are generally described in detail, while the main users of Chinese dialects - the rural population - are described simply in annals of the administrative divisions of the region. For the records of administrative geography, other sources of information are mainly boundary information on the inscriptions of each village, or the records of new and old genealogical prefaces in genealogies, ancestors' business history, country maps, geography, and changes in administrative divisions of a genealogy. Taking the paper genealogy of Liao's audiovisual genealogy, "Coral Liao's Genealogy" as an example, the "Praise Names" in Volume One recorded the origin of Coral Village and changes in administrative divisions in more detail. Part of the record of the origin of Coral Village reads thus: "The ancestor Liao Wenshi came to Zhejiang from Shanghang County, Tingzhou Prefecture, Fujian Province, Gutian, and then lived in Jiangshan County to Tangyi Daishang, married with his first wife, and moved to Sanhu in the tenth year of Yongzheng (1732). and settled there. Because the village is located in a small basin surrounded by mountains, it looks like a small lake, so it has been called Mountain Lake, Three Harmonious Lakes, and finally Coral, and the village owner's name is Liao." This record was later transferred from the Coral genealogy to "Jinhua County Chronicles." Coral's administrative divisions are also recorded in more detail in the genealogy: Taoyuan Township, Tangxi County in 1949; Coral Administrative Village, Shitang Township in 1951; Yinling Production Team, Tashi Management District, Jiufeng People's Commune, Jinhua County. In the years1958 to 1961 it belonged to Shankeng People's Commune Yinling Brigade; Shankeng Commune Coral Brigade in 1964; Shankeng Township Coral Village Committee in 1983; Coral Village Committee of Tashi Township in May 1992. The above content was later recorded in the county chronicles. It can be seen that the geographical information of genealogy plays an important supplementary role to the official history and cannot be ignored. Regarding the boundary of Shanhu Village, it can be obtained from the township map part of the family tree.

From the geographic information on the family tree, the specific geographic location and administrative division of Coral Village can be deduced. The unrecorded year information is the Qing Dynasty. You can refer to the detailed content of Zongyingji, the new and old prefaces in the genealogy, and supplement it with the records of the county in the corresponding historical period and the travels of celebrities. Just like "The Family Tree of the Coral Liao Family", in geographical language research, the related materials of the family tree administrative division have an irreplaceable role in connecting historical administrative divisions with complex dialect patterns in small areas. By determining administrative divisions, it is possible to further analyze the inter-communication (including the degree of understanding) and the formation process of the geographical dialect continuum. From documents or materials other than genealogy, we cannot obtain such detailed, regular and time-sensitive administrative division information.

\section{The relationship between the migration history of the family tree and the dialect}

The geographic dialect continuum is the diffusion of language features, and the geographic displacement of language features is the most essential feature of the geographic continuum. The displacement of language 
Figure 1. Statistics on the number of students in domestic data structure courses

\begin{tabular}{|c|c|c|c|c|c|c|}
\hline $\begin{array}{l}\text { Migration } \\
\text { sequence }\end{array}$ & $\begin{array}{l}\text { Ancestors'g- } \\
\text { iven name }\end{array}$ & Generation & $\begin{array}{c}\text { Time of } \\
\text { migration }\end{array}$ & Old place & Reasons of migration & Migration of destination \\
\hline 1 & Shuan & 1 & $\begin{array}{l}\text { Zhou } \\
\text { Dynasty }\end{array}$ & unknown & $\begin{array}{l}\text { ennobled with Family name 稀 } \\
\text { in Runan county }\end{array}$ & $\begin{array}{l}\text { Runan county (now in } \\
\text { Henan Province) }\end{array}$ \\
\hline 2 & Bo & 32 & $\begin{array}{l}\text { Chunqiu } \\
\text { period }\end{array}$ & $\begin{array}{l}\text { Runan county(speculated } \\
\text { from residence place of } \\
\text { ancestor and offspring } \\
\text { Chongde) }\end{array}$ & $\begin{array}{l}\text { no(marked with left to } \\
\text { Fengguang during Chunqiu } \\
\text { period and change family name } \\
\text { from 通翏 into Liao) }\end{array}$ & $\begin{array}{l}\text { Runan county (now in } \\
\text { Henan Province) }\end{array}$ \\
\hline 3 & Hui & 42 & Qin Dynasty & $\begin{array}{l}\text { Runan county(speculated } \\
\text { from residence place of } \\
\text { ancestor and offspring } \\
\text { Chongde) }\end{array}$ & $\begin{array}{l}\text { Qin Zheng was tyrannical and } \\
\text { escaped chaos to Yancheng(now } \\
\text { in Shandong Province),remigrate } \\
\text { Henan Province }\end{array}$ & $\begin{array}{l}\text { Runan county (now in } \\
\text { Henan Province) }\end{array}$ \\
\hline 4 & Jie & 51 & $\begin{array}{l}\text { The Period } \\
\text { of Emperor } \\
\text { Xiaoming } \\
\text { in the Han } \\
\text { Dynasty }\end{array}$ & $\begin{array}{l}\text { Runan county(speculated } \\
\text { from residence place of } \\
\text { ancestor and offspring } \\
\text { Chongde) }\end{array}$ & $\begin{array}{l}\text { be an official called Pusiqin } \\
\text { during the Period of Emperor } \\
\text { Xiaoming of the Han Dynasty }\end{array}$ & Luoyang \\
\hline 5 & Congxian & 61 & Xijin & Luoyang City & no & $\begin{array}{l}\text { Songyang county Zhejiang } \\
\text { Province }\end{array}$ \\
\hline 6 & Qin & 63 & unknown & $\begin{array}{l}\text { Zhejiang } \\
\text { Province(speculated from } \\
\text { residence place of ancestor } \\
\text { Congxian ) }\end{array}$ & $\begin{array}{l}\text { be an official to protect } \\
\text { Fengzhou }\end{array}$ & Fengzhou(now in Vietnem \\
\hline 7 & Chengxi & 64 & unknown & Fengzhou & $\begin{array}{l}\text { be an official as Taishou in } \\
\text { Yangzhou }\end{array}$ & $\begin{array}{l}\text { migrated to Nankang } \\
\text { County (now in Ningdu) }\end{array}$ \\
\hline 8 & Yanguang & 66 & unknown & $\begin{array}{l}\text { Nankang County(speculated } \\
\text { from residence place of } \\
\text { ancestor ) }\end{array}$ & $\begin{array}{l}\text { be an official as Tongpan in } \\
\text { Fuzhou }\end{array}$ & $\begin{array}{l}\text { Nankang County } \\
\text { (speculated from residence } \\
\text { place of ancestor ) }\end{array}$ \\
\hline 9 & Chongde & 71 & unknown & $\begin{array}{l}\text { Nankang County(speculated } \\
\text { from residence place of } \\
\text { ancestor ) }\end{array}$ & $\begin{array}{l}\text { be an official as county leader in } \\
\text { Suihua }\end{array}$ & Wuwei County \\
\hline 10 & Guangjing & 73 & $\begin{array}{l}\text { Tang } \\
\text { Dynasty }\end{array}$ & Wuwei County & be an official as Cishi in Jizhou & Luoyang \\
\hline 11 & $\begin{array}{l}\text { Forty-one } \\
\quad \text { lang }\end{array}$ & 75 & $\begin{array}{l}\text { Tang } \\
\text { Dynasty }\end{array}$ & Luoyang City & no & $\begin{array}{l}\text { Ninghuashibi(now in } \\
\text { Fujian) }\end{array}$ \\
\hline 12 & Wenxin & 79 & $\begin{array}{l}\text { Song } \\
\text { Dynasty }\end{array}$ & $\begin{array}{l}\text { Ninghuashibi(Now Ninghua } \\
\text { county Fujian province } \\
\text { speculated from residence } \\
\text { place of ancestor ) }\end{array}$ & be an official as Canzhengdafu & $\begin{array}{l}\text { Home is in Fujian and } \\
\text { worked in Kaifeng } \\
\text { (speculated from the } \\
\text { information of ancestor) }\end{array}$ \\
\hline 13 & Hua & 80 & $\begin{array}{l}\text { Song } \\
\text { Dynasty }\end{array}$ & $\begin{array}{l}\text { Ninghuashibi(Now Ninghua } \\
\text { county Fujian province } \\
\text { speculated from residence } \\
\text { place of ancestor ) }\end{array}$ & be an official as Canzhengdafu & $\begin{array}{l}\text { Gutian Weiwu County, } \\
\text { Shanghang County, } \\
\text { Tingzhou Fu }\end{array}$ \\
\hline 14 & & & $\begin{array}{l}\text { In the fifty- } \\
\text { second year } \\
\text { of Kangxi's } \\
\text { reign } \\
\text { in Qing } \\
\text { Dynasty }\end{array}$ & $\begin{array}{l}\text { Gutian Weiwu County, } \\
\text { Shanghang County, } \\
\text { Tingzhou Fu }\end{array}$ & $\begin{array}{l}\text { Gutian county in fujian province } \\
\text { was overwhelmed and that } \\
\text { forced to move to Zhejiang. }\end{array}$ & $\begin{array}{l}\text { Jiangshan ,Zhejiang } \\
\text { province }\end{array}$ \\
\hline 15 & & & unknown & $\begin{array}{l}\text { Jiangshan,Zhejiang } \\
\text { Province }\end{array}$ & no & Lanxi,Zhejiang Province \\
\hline 16 & Wenshi & 97 & $\begin{array}{l}\text { The first } \\
\text { year of } \\
\text { Emperor } \\
\text { Yongzheng } \\
\text { in Qing } \\
\text { Dynasty }\end{array}$ & Lanxi,Zhejiang Province & $\begin{array}{l}\text { scarce employment } \\
\text { opportunities }\end{array}$ & $\begin{array}{l}\text { Tangyi (Tangxi county) } \\
\text { mountain area }\end{array}$ \\
\hline 17 & & & unknown & $\begin{array}{l}\text { Tangyi (Tangxi county) } \\
\text { mountain area }\end{array}$ & got married with his wife & Daishang Tashi village \\
\hline 18 & & & $\begin{array}{l}\text { The fourth } \\
\text { year of } \\
\text { Emperor } \\
\text { Yongzheng } \\
\text { in Qing } \\
\text { Dynasty }\end{array}$ & Daishang Tashi village & $\begin{array}{l}\text { was bullied by his wife's } \\
\text { parents }\end{array}$ & Created Sanhu village \\
\hline
\end{tabular}


features within the continuum corresponds to the migration activities of the individual subjects of the study, namely the language users. Therefore, in addition to the historical evolution of administrative divisions, population migration in the survey sites is another very important factor affecting language evolution. The study of the history of local population migration is the most basic requirement for discussing the history of language evolution. China's old local chronicles rarely discuss in detail the migration of residents, the relevant records are simple, and the value of linguistic research is limited. In addition, other descriptions of historical population migration events in historical materials on population migration or in old works by celebrities are mostly generalized large-scale population migration, and rarely involve specific information about population migration at the township or village level. It should be understood that despite the high rate of urban population mobility, the language changes in these areas are mostly reflected in the transient lexical variations on the surface, and the phonetic and grammatical variations are not obvious. Generally speaking, the lower the administrative level and the farther the geographical location is from the economic, political and cultural center, the greater the possibility of substantial distortion of language features in the language collection. Therefore, it is certainly not sufficient to discuss the relationship between language change and population migration based on the traditional historical data on population migration(Table 1). He Dengsong believes that besides tombstones, monuments in rural temples, and lists of donors engraved on clocks, one of the most important sources of historical data on resident migration is genealogy ${ }^{[5]}$.

Here we take the traditional paper genealogy "Coral Liao's Genealogy", the primary source of data of audiovisual family tree of the Coral Liao family, as an example. By combing his lineage to obtain the migration situation of the Liao family ancestry of Coral Village (see the table below), we find that the Coral ancestor was originally a resident of the Mandarin district, and the descendants of the Coral Village had at least 18 relocation behaviors due to wars and taking up a government post. The 98th generation, Liao Wenshi was forced to move to Zhejiang because of overcrowding in Gutian County, Fujian Province, his ancestral home.

The table shows in more detail the migration of the ancestors of the Liao family of Coral Village since the Zhou Dynasty.However, some the family tree's direct migration context is not clear. Many migration behaviors in the table need to be inferred from the family tree content. For example, in the seventythird generation of Liao Guangjing, the information in the family tree, except for his spouse and children, only contains a few words "Daonan, hold the post of Jizhou governor". The information on his hometown, "Wuwei County," was inferred from his father Liao Lanzhi's genealogy information. Liao Lanzhi did not move, so his son must have grown up in Wuwei County where he lived. From the Tang Dynasty Jizhou provincial governor's post and his daughter-in-law's companion Feng "went to Beijing in Tianbao Guiwei year of Tang dynasty "we can presumably learned that Liao Guangjing's family moved to the then capital of Chang'an. As we all know, a large number of the villages in China started from the settlement of a single family. For example, Houzhang Village, Xiazhang Village, and Chenjia Village in Jinhua City were developed by Zhang (张), Zhang (章), and Chen (陈) clans. In these three villages there are still many villagers named Zhang (张), Zhang (章) and Chen

(陈). Therefore, the study of language evolution in rural areas of China, especially in the non-Mandarin areas with a wide variety of dialects and complex accents, needs to be analyzed with the historical context of family migration.

\section{The migration of ethnic surname witnesses dialect variants}

Geopolitics and synchronicity are two relatively independent aspects in language evolution. The migration of ethnic surnames belongs to geographic displacement. Dialect variation is a diachronic evolution. It seems impossible to witness the diachronic phenomenon by geographic displacement. In fact, it is "that kind of regional variant of the language form that expresses a specific meaning, or the time inferred from the geographical distribution of the variant. That is, the embodiment of geography in the time variable. Geographic linguistics and historical linguistics are similar in that they both focus on studying the temporal changes of language as their main emphasis ${ }^{[6]}$. Geolinguistics is the study of language evolution across time-space dimensions. As mentioned above, dialect audiovisual genealogy achieves synchronic research across generations (time dimension) in the genealogy, and obtains the language variation of the same group (family tree members) regardless of geographic 
displacement or intergenerational life spanning any variable. Therefore, the relevant facts of temporal and spatial displacement in the family tree of Shan $\mathrm{Hu}$ Liao can be used to support the formation of the Hakka dialect and the evolution of the Shan $\mathrm{Hu}$ dialect.

Starting in the Spring and Autumn Period, Liao's ancestors got ' Liao'this family name from dominator and the ancestors of Coral Village have moved many times in history. Qin Zheng was tyrannical and escaped chaos to Henan, some officials moved to Luoyang and then to Zhejiang, and some moved to Fengzhou (now in Hanoi, Vietnam), Yangzhou, Fuzhou, Wuwei County (now in Shaanxi), Jizhou and other places. By the 75th generation of Liao's Coral lineage, Liao Siyilang and Pei Liu moved to the Ning Fossil Cliff (now in Ninghua County, Fujian Province, known as the ancestral land of the Hakka people and one of the birthplaces of Hakka culture). The time of their migration is not given in the spectrum (see table). According to Feng's introduction, "went to Beijing and died on the way and was buried under Huang Jing's tree and had given birth to a son Forty-One Lang in Kui Wei Suiqin Tianbao year of Tang Dynasty “ and his elder Linxuan." used martial arts to give silver to doctor Qing Guanglu in Xuanzong year of Tang Dynasty. The former commander of the Baisheng Army moved his son to Huguang." It can be inferred that Forty-One Lang moved to Ninghua, Fujian during the Tang Tianbao period.Coral villagers have always remembered Liao Siyilang's descendant Liao Hua as the ancestor of Fujian, mainly because Liao Hua used to be a Canzhengdafu in politics. According to genealogy, it was confirmed by the descendants of Coral Village that Liao Hua is the first ancestor who moved to Shanghang County, Fujian. The descendants of the Liao family in Shanhu Village regarded Liaohua as "the ancestor of the Liao family in Wuwei County, Wuwei County, Gutian, Fujian Province". The Coral dialect evolved from the Hakka dialect, and its pronunciation, grammar and vocabulary are almost all inherited from the Hakka dialect, while being influenced by the local $\mathrm{Wu}$ and Tangxi dialects. The formation of the Coral language should be traced back to at least Liao Forty-one Lang who live in Tang Dynasty. His migration behavior - moving from Luoyang to Ninghua County, Fujian Province - changed the language environment of his son Liao Guoqing, resulting in the Coral Liao family to move from the original Mandarin area to Fujian, the birthplace of the Hakka. However, during the Xuanzong period of the
Tang Dynasty, the Hakka dialect had not yet formed. It was not until the Huangchao Uprising that occurred in the late Tang Dynasty that people were forced at that time to disperse and avoid chaos, triggering some people from northwestern and central Jiangxi to move into the mountainous areas of southern Jiangxi, isolated from the influence of the northern dialect at that time. These provide excellent environment for the formation of Hakka dialect ${ }^{[7]}$. Earlier research had established that the Hakka dialect was established during the Song Dynasty. In other words, starting from Liao Guoqing, the son of Liao Siyilang, the Liao clan people living in Ninghua, Fujian witnessed the historical process of the formation and development of the Hakka dialect. Therefore, the ancestor Liao Wenshi of Shanhu Liao is actually the earliest Hakka dialect speaker in Fujian. The earlier Shanhua dialect is one of the embryonic forms of the early Hakka dialect, and it has not experienced the cumulative effects of the linguistic difference. Therefore, it can be assumed that if the Coral Dialect hypothesis is stripped the Wu dialect's influencing performance factors, it will reflect the language characteristics of some Hakka dialects in its formation, which is worthy of research.

At the same time, the Shanhu Liao family brought the Hakka dialect into the mountainous area of Tangxi County through Liao Wenshi, the 97th generation of the Liao family. Liao Wenshi's Hakka dialect and the Wu dialect's Tangxi dialect have a neighbor effect (neighborhood effect), and there are language variations. For example, the tones Yin $\mathrm{Qu}$ [323] and Yang Qu [214] are merging, the preposition “和 " [kuo45] is gradually being replaced by "Bang" [pos334], and the Coral Dialect has borrowed an assortment of Wu Tangxi dialect vocabulary ${ }^{[8]}$. This eventually became a Hakka dialect island in the Tangxi dialect of the $\mathrm{Wu}$ language.. Therefore, it can be combined with the local chronicles and monographs of Ninghua and Shanghang County in Fujian and the genealogy of Liao's Fujian line to clarify the acquisition conditions of Liao's Coral dialect in Shanhu Village.

The ancestors of Shan Hu Liao witnessed the formation of the Hakka dialect, and at the same time brought it into the $\mathrm{Wu}$ dialect area, which promoted the mutation of the Hakka dialect to form the Coral dialect, which has important practical value for the formation and variations of the Hakka dialect.

In addition to the above three aspects of the interaction between geography and dialects, it is also 
necessary to pay attention to psychology geo-identity of Pumin (People in the family tree). Geo-identity is a sense of belonging to the place of residence, the relationship between people in this area, and the humanistic landscape. The act of revising the tree is the most direct and serious manifestation of geographic identity $^{[9-10]}$. Blood relationship and geography have always influenced each other and are inseparable. The geographical identity of Chinese society coexists in the spiritual world of each individual society due to the long accumulation of traditional culture. Different from the influence of kinship on the acquisition of native dialects, the importance of the sense of geographical belonging to dialect inheritance is more obvious. Kinship awareness and geographic identity are essentially unified. They are emotional support for relatives and familiar human and geographic environments. They are subjective factors for people's persistence in using dialects.

As the record of the family, family tree record in detail personal information such as the migration, birth and death years of clan members, reflecting important content such as genealogy, history, property, humanities, and scenery. They are valuable historical materials of human geography in a place, and they are also important literature resources for the study of local language history. We believes that the geographical factors of genealogy data, whether it is administrative division, population migration, geographic identity, or the human deeds related to dialect evolution reflected in the genealogy, can smoothly break through the comparative research based on real-time survey data of several generations, and provides a basis for describing language innovation and diffusion, and provides irreplaceable research value for language evolution research.

\section{References}

[1] An introduction to the specific development of audiovisual genealogy will be written in a separate article. For the relevant introduction, please refer to Xi Jiajia's Master's degree thesis, "Research on Dialect Audiovisual Genealogy Template System - Taking Liao's Audiovisual Genealogy as an Example."

[2] J.K.Chambers, Peter Trudgill, 2016. Dialects Learn the Tutorial, second edition, 11-234, Peking University Press, Beijing

[3] You Rujie, Zhou Zhenhe ,1984. The relation between dialect geography and Historical administrative geography_ Taking the Dialect Division of Zhejiang as an Example. Journal of Fudan University Social Science Edition, 2

[4] W. Grootaers. traductor Iwata Ray, 2003, Chinese Dialect Geography[M]. Shanghai Educational Publishing House, Shanghai

[5] Shibata Takeshi, 2018.Methods of Linguistic Geography, China Commerce and Trade Press Beijing 5-188

[6] Zhou Zhenhe, 1988. The General Trend of Immigration in Chinese History and Its Influence on Chinese Dialect Deography, Human Geography abroad, 1

[7] Cao Zhiyun,2003. The Situation of Dialects in Shanhu Village, Jinhua, Zhejiang, Chinese Social Linguistics1

[8] Xiao Wenyan, 2012. Geographical identity: the Psychological Consensus of Hakka Overseas Chinese and Overseas Chinese District Society_- Taking Meizhou Guangzhou in the late Qing Dynasty and the early Republic of China as an Example, Jiangxi Social Sciences, 11

[9] You Rujie, Zhou Zhenhe ,1986. The Relation between demographic change and Language evolution, Shanghai Academy of Social Sciences academic quarterly journal, 4

[10] Coral village Liao genealogy, the first volume, Qing Dynasty, Coral village Liao genealogy, the second volume, Qing Dynasty 